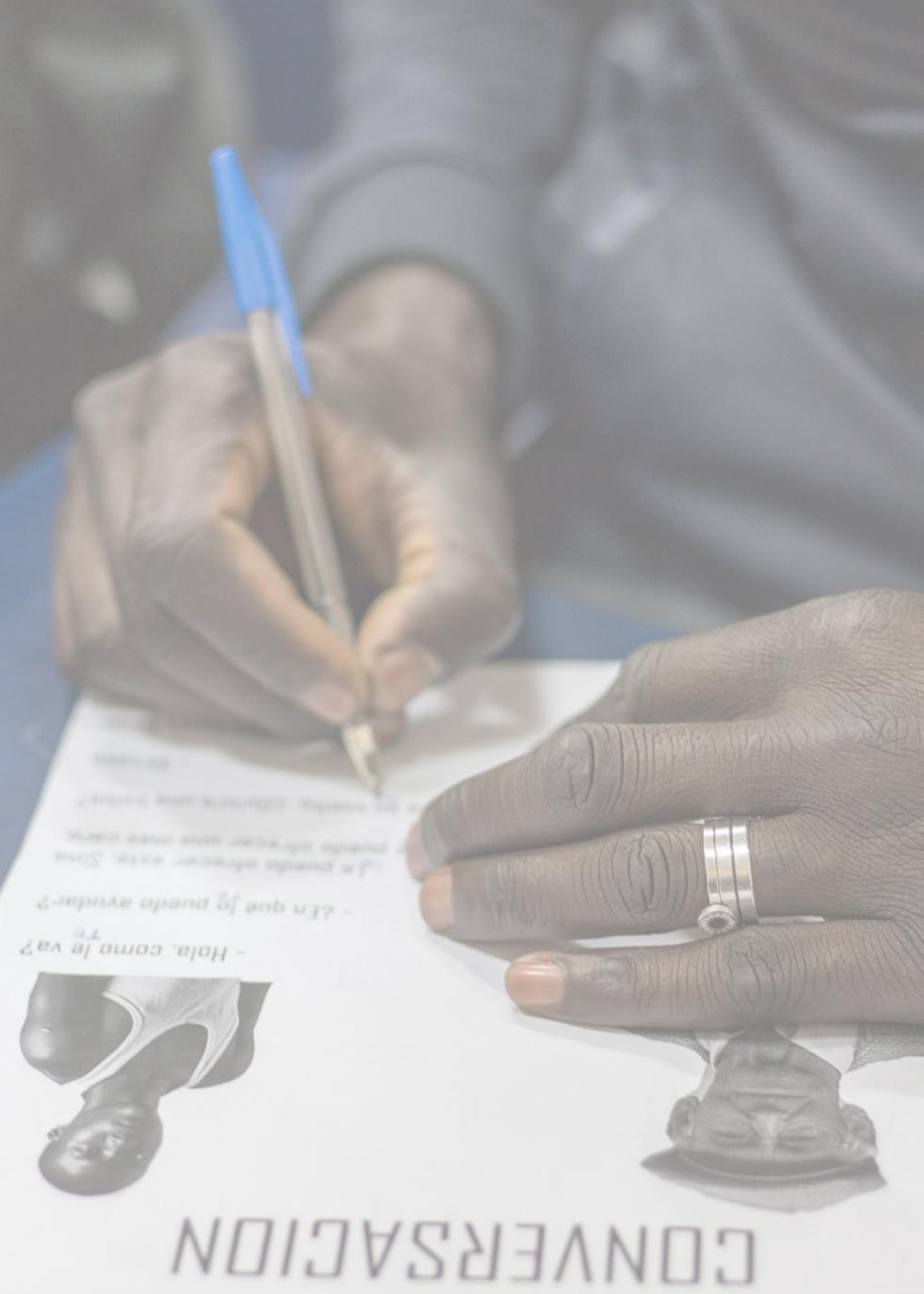




\title{
Hacia la necesaria superación de algunos mitos de la universidad venezolana
}

\author{
LEONARDO CARVAJAL
}

Docente ucevista por 22 años, ahora docente ucabista por 20 años. Doctor en Filosofía y Ciencias de la Educación, docente de tiempo completo, investigador y escritor.

\begin{abstract}
RESUMEN
La universidad está obligada a superar mitos y pensamientos anacrónicos en cuanto a su propia concepción y funcionamiento. Ha permanecido como una institución crítica y bastante lúcida en cuanto a las investigaciones sociales, aunque conservadora y miope para mirarse a sí misma. Se recapitulan en este artículo varios de los cuestionamientos que he realizado en las últimas décadas acerca de los modos fosilizados que tiene la universidad venezolana de pensarse a sí misma, lo que quiere decir: dogmatizar el concepto de autonomía; continuar con el uso de la trilogía medieval de conceptos: campus, cátedra y claustro; creer que la tarea universitaria es "buscar la verdad"; considerarse la institución monopolizadora de la creación del conocimiento; mantener la formulación de docencia, investigación y extensión como sus funciones básicas (a las que opongo la formulación de enseñanza-aprendizaje, investigación y gerencia); conservar un modelo gerencial de la vida académica sordo y ciego a los aportes que hizo Montesquieu a la modernidad; persistir en un modelo laboral desalentador; guiarse por la ficción romántica de que todo docente universitario debe ser un investigador, aunque la realidad sea ajena a esa fantasía.
\end{abstract}

Palabras clave

Mitos universitarios, autonomía universitaria, funciones de la universidad, docente-investigador. 


\title{
A review to the necessary debunking of Venezuelan university myths
}

\begin{abstract}
The Venezuelan university has the obligation of debunking myths and anachronic thoughts about its conception and function. University has been a critic and lucid institution when it has studied society, but conservative and blind to look at itself. In this article, I recapitulate questions about the Venezuelan university's own notion, for instance: to dogmatize the concept of autonomy; to continue using the medieval concept of trilogy of campus, teaching and cloisters; to believe that the university task is "to search the truth"; to think that university is the monopolistic institution of creation of knowledge; to maintain the formulation of teaching, researching and extension as its basic functions (I oppose the formulation of teaching-learning, researching-managing); to preserve a management model of the academic life which is deaf and blind to the contribution that Montesquieu made to the modernity; to persist in a disincentive labor model; to be guided by the romantic idea that every university student must be a researcher, although the reality is far from that fantasy.
\end{abstract}

Key words

University myths, University autonomy, University functions, Teacher-researcher.

\section{Rumo à necessária superação de alguns mitos da Universidade Venezuelana}

\section{LEONARDO CARVAJAL}

\section{Sumário}

A Universidade é obrigada a superar mitos e pensamentos anacrônicos sobre sua própria conceição e funcionamento. Ela tem sido uma instituição muito crítica e lúcida quanto pesquisas na sociedade, ainda que conservadora e míope para se olhar a si mesma. Se repetem sumáriamente neste artigo algumas das questões que venho fazendo nas últimas décadas sobre as fossilizadas formas que tem a Universidade Venezuelana de se pensar a si mesma, quer dizer: dogmatizando o conceito de autonomia; continuando o uso da trilogia medieval de conceitos: campus, cadeira e claustro; acreditando que a tarefa da Universidade é "procurar a verdade"; se acreditando como a instituição monopolizadora da criação de conhecimento; mantendo a formulação de ensino, pesquisa e extensão como sua função básica (à qual oponho a formulação ensino-aprendizagem, pesquisa e gestão); preservando um modelo gerencial de vida acadêmica surda e cega às contribuições que fez Montesquieu à modernidade; persistindo num modelo de trabalho desanimador; se guiando pela ficção romântica de que todo professor universitário precisa ser pesquisador, embora a realidade seja estranha a essa fantasia.

\section{Palavras-chave}

Mitos universitários, autonomia universitária, funções da Universidade, professor-pesquisador. 


\section{La modernización de la autonomía, pero no al estilo medieval}

Si examinamos instituciones de la sociedad venezolana como la económica, la militar, la eclesiástica y la educativa, no queda la menor duda de que la universidad es una de las instituciones más conservadoras. Es claro que toda institución debe mantener una tensión dialéctica entre la preservación de su identidad y la necesidad de renovación para poder mantener su pertinencia ante los cambios de su entorno, debido a esto, es necesario tener permanentemente una actitud favorable ante la renovación de la institución, para que esta no tenga que pagar el precio de ser atrapada por una obsolescencia que no se advirtió a tiempo. De allí que no sea conveniente aferrarse a conceptos de manera dogmática. Mi posición es que todo debe ser discutido y recurrentemente sometido al "libre examen", bajo la pena de fosilizar el pensamiento y la acción. Y cuando digo todo, es todo, incluyendo el que para muchos es el sagrado concepto de autonomía. (Carvajal, 2012)

Observemos el ejemplo de la sacralización indebida del principio de autonomía y cómo personas muy respetables a finales del siglo Xx formularon, con la mejor de las intenciones, enfoques refractarios a la discusión de ese criterio medular. Así, el entonces vicerrector José María Cadenas declaró que, en noviembre de 1994, el equipo rectoral de la UCV "rechazaría la idea de revisar la autonomía universitaria” (Leal, A., 1994, D-7). Y un exrector de la misma institución, Carlos Alberto Moros Ghersi, por esos mismos días, apoyó esta postura al sentenciar tajantemente que el concepto de autonomía "no admite discusión", y esto porque -tal cual un mito de origen-, esa autonomía "es una potestad que surge con las primeras instituciones del medioevo" (Colomine, 1994, D-1). Y otros incluso iban más allá, como el entonces rector de la UCV, Simón Muñoz, quien expresamente equiparaba a la universidad con la iglesia, al indicar que "gracias a la autonomía, las universidades han sido como la iglesia: han persistido a través de los siglos y a través de los sistemas y han sido refugio de las mejores causas..." (Muñoz, 1994, C-3).

Basten estas referencias para ilustrar la desviación defensiva que se fue entronizando en los espacios universitarios venezolanos: sacralizar o mitificar algunos o muchos de los rasgos del modelo conceptual-normativo-operacional de la institución. Se llegó al extremo de compararla con la institución eclesial, obviando que en su ethos ambas instituciones podrían ser más bien antitéticas, puesto que una se basa en la revelación, la fe y los dogmas; mientras que la otra se basa en la razón y la investigación científica. Así la primera tendría justificación para ser conservadora y poco dada a la duda metódica, mientras que la segunda, por el contrario, perdería su razón de ser si quisiera fundarse sobre dogmas y tabúes. Pero es que, además, Ángel 
Lombardi, por ese entonces rector de la Universidad del Zulia y luego rector de la Universidad Católica Cecilio Acosta, replicaba contra la inconveniente equiparación de la universidad con la iglesia, explicando que incluso la dos veces milenaria Iglesia Católica había decidido renovarse a profundidad, y que los líderes religiosos del Concilio Vaticano II no habían asumido posturas timoratas y conservadoras. En su lugar, la tesis de estos líderes, como la de Juan XXIII, fue: "La Iglesia ha estado por siglos con las ventanas cerradas. Vamos a abrirlas aunque haya riesgo de pulmonía" (Lombardi, 1995, p. 9).

Finalizo la mención de este asunto medular, la autonomía, indicando que el enfoque adecuado para tratarlo es el histórico, tal cual lo planteó en un esclarecedor texto César Villarroel al señalar que, en el fragmentado mundo político feudal, la autonomía "era la muralla jurídica de las universidades", mientras que en la época contemporánea "la universidad deja de ser un estado frente al Estado", y, por lo tanto, han de modificarse varios de los rasgos de su autonomía (Villarroel, 1990, pp. 40-43).

En efecto, la universidad contemporánea carece, por ejemplo, de autonomía financiera. Bastaría citar el caso de aquella Universidad Central de Venezuela, autosuficiente y boyante en lo económico, que nos legaron Simón Bolívar y José María Vargas, con un patrimonio de siete prósperas haciendas de cacao, caña de azúcar, café y una veintena de casas para arrendamiento (Leal, I., 1981, pp. 176-180), la cual pasó, desde la época de Antonio Guzmán Blanco, hacia finales del siglo XIX, a ser una universidad dependiente de los fondos que le proporcionara el Estado, lo cual no ha variado desde entonces.

\section{Conceptos básicos anacrónicos}

Lamentablemente se ha hecho muy poco en las universidades en dirección de renovar conceptos. En un evento sobre reformas para la educación superior invité a pensar lo que significa que, en pleno siglo XXI, se siga manteniendo en el argot universitario (Carvajal, 2013) la trilogía medieval de conceptos: campus, cátedra y claustro. ¿Campus? ¿Campus entendido como un espacio físico cerrado, que goza de inviolabilidad territorial, y en el cual se reúnen los profesores y los estudiantes, en una era en la que el docente se puede "encontrar" con sus estudiantes en cualquier rincón del planeta gracias al Internet? ¿Cátedra? ¿No era ella acaso una suerte de "trono académico" desde el cual el maestro medieval leía la tesis del día que luego explicaría con el fin de que sus alumnos la repitieran, según la fórmula lectio-explicatio-repetitio? ¿No está acaso asociada la cátedra al magister dixit, o lo que quiere decir, al principio de autoridad, tanto que, según las normas de la Iglesia Católica, cuando el Papa habla ex cathedra, desde la cátedra, su palabra es infalible? ¿Y claustro? ¿Por qué claustro y no congreso, asamblea o encuentro? ¿Acaso claustro en su origen latino no significa cerrojo, barrera, clausura? Todos ellos apelativos muy pertinentes para las reuniones conventuales, pero nada convenientes para una institución que debe ser transparente y estar abierta a múltiples conexiones con la sociedad.

Invito también a reflexionar sobre lo desfasado de la formulación -que figura en el artículo $1^{\circ}$ de nuestra Ley de Universidades y en los cuerpos 
normativos internos de nuestras instituciones universitarias- acerca del propósito fundamental de las universidades. Allí se declara: "La universidad es fundamentalmente una comunidad de intereses espirituales que reúne a profesores y estudiantes en la tarea de buscar la verdad..."

¿Buscar la verdad? ¿Existe acaso la verdad, una presunta única y mayúscula verdad? ¿Existen acaso únicas verdades para cada asunto ubicadas en los presuntos anaqueles de un mundo objetivo, al cual accederían los esforzados investigadores y las encontrarían? No voy a hacer reflexiones filosóficas al respecto, que muchas cabrían. Solo diré que en el conjunto de las centenares de ciencias que se cultivan en el planeta, existen miles de teorías que tratan de interpretar los más variados fenómenos $\mathrm{y}$, constantemente, las diversas constelaciones teóricas van cediendo su preeminencia a otras que, de manera temporal, explican mejor la realidad, pasando así las desplazadas a formar parte de los museos arqueológicos contentivos de teorías y métodos científicos. ¿Buscar la verdad bajo el supuesto de que existe una única verdad? Provoca recordar el escepticismo del mandatario romano que se preguntaba cuál era la verdad. A él lo evocaba años atrás Caracciolo Parra Pérez al señalar que la ciencia histórica se construía en medio de "una controversia interminable”, y se preguntaba con sorna: "¿La Verdad con mayúscula? Aquí te quiero, Pilatos" (Parra Pérez, 1943, p. 296). En unos cuantos centros universitarios, además de formar profesionales, se produce conocimiento. No en demasía, es verdad, si diéramos por certero el estimado hecho por Orlando Albornoz de que, para finales del siglo $\mathrm{XX}$, de las 812 universidades latinoamericanas apenas 45 podían ser consideradas como espacios cognitivos de nivel superior (Albornoz, 1997, p. 35; Brunner, 1990, p. 139). 


\section{La "Santísima Trinidad" de docencia, investigación y extensión}

De manera rutinaria, e incluso dogmática, se señala que la universidad tiene tres grandes funciones: docencia, investigación y extensión. Esta manera de pensar se ha convertido en una doctrina oficial y en norma jurídica. Me permitiré someterla a discusión con algunos argumentos, adelantando que considero más razonable sostener que las tres funciones de la universidad son: enseñanza-aprendizaje; investigación y gerencia.

¿Por qué no “docencia”? Porque denominar así a la función implicaría poner todo el foco de atención en la actividad de enseñanza que desarrollan los profesores. De esta manera sucedía en la época del magister dixit: el maestro enseñaba y los alumnos repetían. Pero, así como sabemos que no pueden existir monedas con una sola cara, tampoco puede existir un maestro sin un aprendiz, ni un proceso de enseñanza sin otro de aprendizaje. Y todo esto sin aludir a teorías específicas, hoy dominantes, como la del Constructivismo, que enfatiza la necesidad de que el maestro tenga muy en cuenta los saberes previos que traen los estudiantes, tesis que, sin tanto empaque teórico, ya había enunciado el pensador Gilbert Keith Chesterton hace un siglo, cuando acuñó: "Si quieres enseñarle inglés a John, más importante que conocer el inglés es conocer a John”. De esta manera, reafirmo que la función se trata de "enseñanza-aprendizaje", y que tiene el propósito de "formar profesionales" en las distintas áreas de la ciencia, las humanidades y la tecnología.

La función de investigación, por su parte, tiene el doble propósito de crear o generar conocimiento científico y de realizar la permanente revisión crítica de los saberes científicos y sociales: los idola de los que habló Bacon hace siglos. Vale destacar al respecto que la investigación en nuestro país está altamente concentrada en el subsistema universitario. Tal hecho es una ventaja comparativa para el sector, pero no es necesariamente conveniente para el país. Jaime Requena destacaba que, para 1999, tan solo nueve investigadores de un total de 1,695 que estaban registrados en el Programa de Promoción del Investigador (PPI) provenían de empresas productivas del sector privado; mientras que 1,409 , un $83 \%$, prestaban servicio en universidades nacionales (Requena, 2003b, p. 22). Y aunque el número de inscritos en 
el PPI se incrementó, Alicia Inciarte reportó que, para el 2004, el 84\% de los investigadores adscritos a él eran personal de universidades públicas (Inciarte et al. 2010, p. 22).

Esta tendencia estaba determinada por el hecho de que, para 1999, el 90\% de los 118 investigadores con más relevancia del PPI, del nivel III y los eméritos, formaba parte del personal de apenas cuatro universidades nacionales (UCV, ULA, USB, LUZ) y el IVIC (Requena, 2003a, pp. 219-221); también para este año de 1999, 94\% de la generación de relevo en investigación, los denominados "candidatos" en el sistema del PPI, laboraba en universidades nacionales (Requena, 2003a, p. 220).

Una minoría de centros universitarios aglutinaba, y aglutina todavía, al grueso de los investigadores del país, a la par que, en estas universidades, los que califican como investigadores son tan solo un pequeño subgrupo dentro del personal de planta. Eduardo Castillo reveló que, para 1995, "menos del 13\% del personal académico de tiempo completo (TC) y dedicación exclusiva (DE) en las universidades realizaba investigaciones de manera regular" (Castillo, 1997, p. 116).

Porcentajes similares calculó también Jaime Requena, quien indicaba que, para 1983, de un total nacional de 12.950 profesores universitarios con DE y TC, tan solo 1.456 fueron considerados como investigadores activos según los criterios del CONICIT; mientras que, para 1999, incluso disminuyó ese porcentaje ya que de $\mathbf{1 5 . 0 7 4}$ profesores universitarios con DE y TC, tan solo 1.409, como ya vimos antes, estaban registrados en el PPI (Requena, 2003a, pp. 244-246).

A partir del análisis de la proyección social y comunitaria de la universidad, diré que no depende de las contemporáneamente denominadas actividades de extensión, lo que quiere decir: cursos de educación continua; trabajos de asesoría para comunidades, empresas o entes estatales; eventos culturales. Considero que el producto de los dos primeros procesos esenciales de la vida universitaria, la enseñanza-aprendizaje y la investigación, constituyen una recurrente proyección hacia las comunidades y las sociedades, concepto que sobrepasa los linderos nacionales. Me refiero a que, cuando una universidad gradúa profesionales, se proyecta en la sociedad.

Por lo tanto, considero un desenfoque creer que la misión social de las instituciones universitarias se cumple tan solo si ellas realizan experiencias directas de relación y contacto y relación entre sus miembros y las comunidades obreras, campesinas o marginales. Pensar así esto significaría aplicar el concepto de sociedad tan solo a los segmentos más pobres de ella. Y también supondría obviar varios esenciales y recurrentes aportes que hizo la universidad al país, tal como la formación de profesionales y la generación de conocimientos.

Y es así, la universidad entrega a su sociedad recurrentes oleadas de nuevos profesionales. Este es el primer canal de aportes a la sociedad. El segundo canal de aportes sustanciales lo conforman los resultados de las investigaciones realizadas que se constituyen en insumos -trátese de la fórmula de la orimulsión o de estudios sobre el Mal de Chagas- para quienes formulan políticas y programas de acción en los diferentes campos de la sociedad. 
Además de estos dos principales aportes, también la universidad interactúa con el país cuando sus miembros, sus dirigentes gremiales, o sus voceros institucionales, fijan posiciones o realizan análisis y propuestas sobre políticas públicas y problemas nacionales. Y esto como contribución al necesario debate democrático y nunca bajo la infundada pretensión de erigirse en alguna suerte de "vanguardia esclarecida del pensamiento".

También lo hace cada vez que se generaliza e incrementa la modalidad de pasantías y servicios sociales comunitarios para los estudiantes. De tal manera que centenares de miles de estos dedican algunos cientos de horas cada año a prestar servicios vinculados con su futura profesión para los segmentos poblacionales más vulnerables. Al hacerlo, por una parte, vivencian los valores de la solidaridad y la corresponsabilidad; por otra, aprenden más sólidamente, porque nada mejor para comprobar y aprehender las teorías que cuando se ponen a prueba en la praxis.

Ahora bien, quiero justificar por qué considero necesario añadir a las dos funciones básicas de la universidad la gerencia, y es por la simple razón de que es esencia de la universidad su autogobierno en lo académico y en lo administrativo. Si ese autogobierno no fuera eficiente, el funcionamiento de la universidad se trabaría y la calidad de sus productos (en formación profesional y en generación de conocimientos) disminuiría intensamente.

Hasta ahora las tareas gerenciales no se han asumido con respeto. Se cree que cualquier excelente académico, con buena voluntad, puede ser decano o rector. Lo que exigen las almas bien intencionadas es que se trate de profesores en los peldaños superiores del escalafón los que ocupen estos cargos, y no los advenedizos politiqueros. Tal exigencia es correcta, pero no es suficiente para asegurar que tales se constituyan en gerentes eficientes de la institución. Que alguien me explique cómo se garantiza, por poner

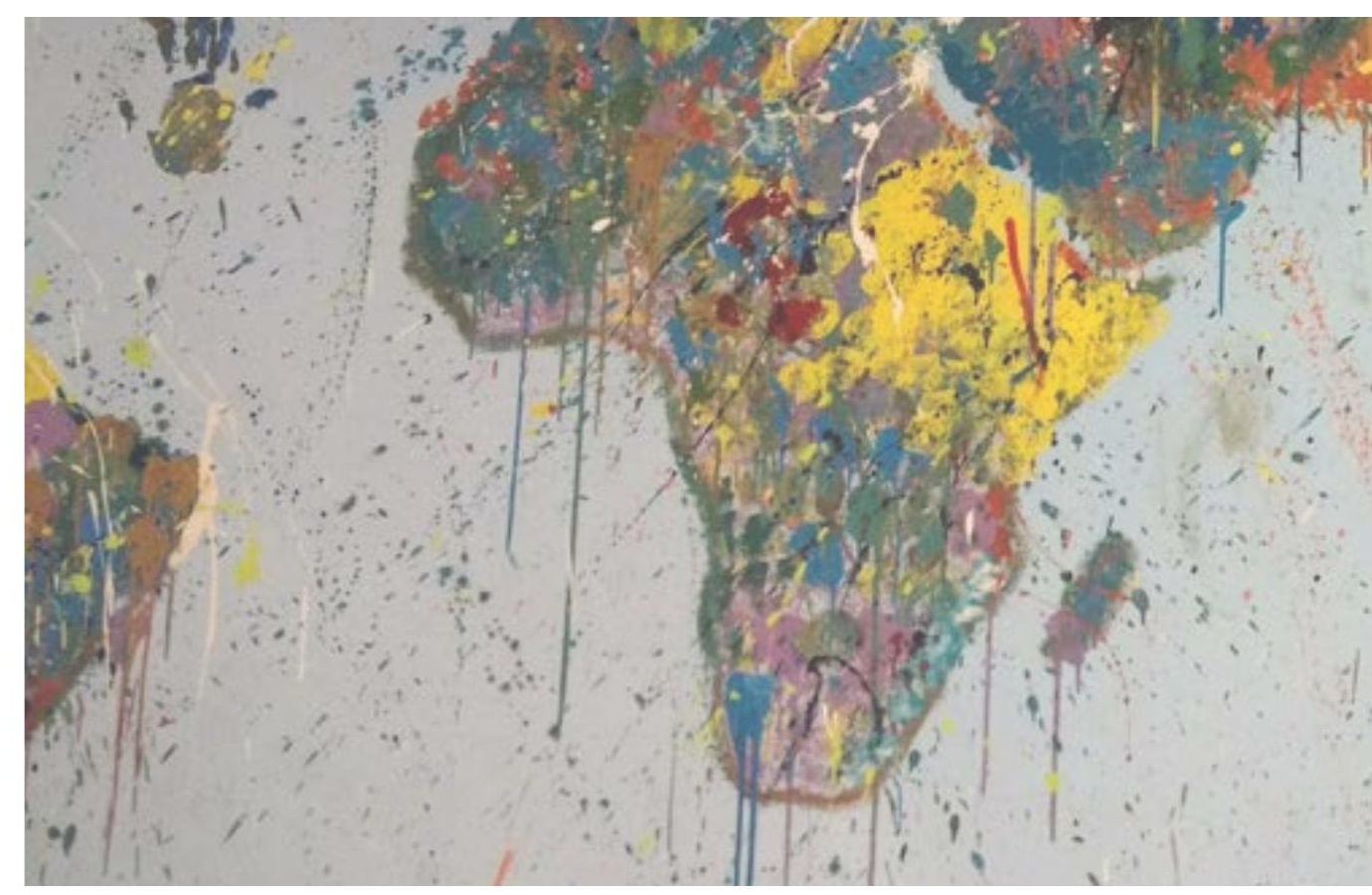


gislativa y jurisdiccional (...) Las consecuencias: no se planifica a mediano y largo plazo; las discusiones estratégicas siempre están postergadas; se decide varias veces sobre lo mismo; las normas deben rehacerse en demasía; no existe un seguimiento del cumplimiento institucional de las políticas y las normas. Modo galimático de desgobierno, en suma, el que emana de esas auténticas "ollas podridas" que son las sesiones de estos órganos de cogobierno (Carvajal, 1991, p. VI).

De allí que postule: a) la división de las funciones de gobierno al interior de las universidades. Deben crearse organismos diferentes que atiendan por separado a lo normativo, lo ejecutivo y lo jurisdiccional; b) referente a los órganos ejecutivos, las competencias deberían desconcentrarse. No es pertinente, por ejemplo, que los consejos universitarios sigan conociendo y aprobando el ingreso y egreso de los profesores cuando esa competencia debería quedar en el ámbito de las escuelas. No se ha entendido que han cambiado las circunstancias y las dimensiones. Lo explico con un ejemplo: cuando el rector Felipe Guevara Rojas, en su enfrentamiento con el profesorado de la Facultad de Medicina de la UCV, en 1912, decidió expulsar a 11 de ellos, estaba desmantelando aquella Facultad, pues la totalidad de su personal docente era de apenas 14 profesores (Carvajal, 2011, p. 22). En cambio, ya en las últimas décadas, esa misma Facultad de la UCV contaba con varios centenares de profesores. ¿Cómo es posible que los trámites para sus ingresos y egresos se mantengan tal cual eran hace un siglo? 


\section{Propuestas para mejorar el inviable modelo gerencial y laboral de la universidad venezolana (lo cual implica superar algunos mitos)}

La universidad venezolana vive momentos sumamente dramáticos a finales de la segunda década del siglo XXI. Ha estado sometida a un implacable acoso por parte de los gobiernos de Hugo Chávez y Nicolás Maduro. Tan solo nuestras universidades autónomas y la Iglesia Católica son las dos instituciones que han resistido el intento gubernamental por controlarlas férreamente. Esta resistencia universitaria ha tenido varios costos, uno de ellos fue la negación de presupuestos mínimamente necesarios para, por lo menos, mantener el ritmo de trabajo académico (en la formación de profesionales y en la investigación) que se tenía planeado para finales del siglo XX.

El despoblamiento de profesores y estudiantes en los últimos años ha adquirido visos de catástrofe. Los salarios de los docentes e investigadores han estado por debajo del salario mínimo que se percibe en un país como Haití. Esto lo dice todo, y explica el éxodo profesoral hacia instituciones de otros países.

Se necesita, para reactivar la vida académica de nuestras universidades, un tratamiento respetuoso por parte de un nuevo gobierno, cualquiera sea su signo ideológico. Pero también las universidades deben prepararse para realizar intensas y extensas reformas de su modelo gerencial y laboral. Si no se hicieran, mi hipótesis es que ni el gobierno más respetuoso y benevolente hacia la universidad podría satisfacer sus requerimientos financieros.

Cambiar el actual modelo supone que no son solo una o dos aristas las que se deben modificar, sino muchas de ellas, para que los ahorros, los mayores ingresos y el uso eficiente del dinero puedan provenir de distintas vías complementarias, con lo cual se asegura efectivamente la sostenibilidad de un nuevo modelo. He propuesto al respecto, desde hace tiempo, una decena de medidas de cambio, complementarias entre sí, y que no agotan todas las que deberían asumirse (Carvajal, 2012, pp. 174178). Estoy consciente de que algunas de ellas chocan contra mitos muy arraigados. Nuevamente las enuncio a continuación.

Primera: Las universidades pueden y deben, sin duda alguna, incrementar los recursos que reciben por concepto de contrato por sus servicios de asesorías y producción tecnológica con instituciones del Estado y con empresas privadas. Pero decir esto no implica plantear la tesis de que ellas deban "autofinanciarse". Esa tesis no la comparto porque la universidad no es una organización económica, sino la prestadora de un servicio público. Pretender obligarlas a "autofinanciarse" sería tan descabellado como exigirle a los hospitales públicos y a los cuerpos policiales que se "autofinancien". Las universidades públicas, en 
cambio, sí deben contribuir parcialmente con su financiamiento mediante la prestación de este tipo de servicios en unas magnitudes razonables, mayores a las actuales.

Segunda: En Venezuela el peso del personal administrativo y obrero en la plantilla total de las universidades gubernamentales es muy alto. Así lo evidenciaba un estudio que hacia finales del siglo pasado mostraba que en la UCAB, privada, el $81 \%$ de su personal era docente y tan solo el $19 \%$ lo era de empleados y obreros; en cambio, tanto en la UCV como en la USB, gubernamentales, la proporción era de 45 y $55 \%$ respectivamente (Salvato, 1999, p. 69). Y en otro estudio se demostró, unos pocos años después, que el conjunto de las universidades gubernamentales venezolanas mantenía, en sus plantillas totales, una relación de $51 \%$ de personal docente y $49 \%$ de personal administrativo y obrero (García Guadilla, 1998, p. 102). Sostengo que, de cara al futuro, la gran mayoría de los servicios que hoy realiza el personal obrero sea prestado mediante contratos de servicio establecidos entre la universidad y las empresas externas a ellas.

Tercera: Muchas de las carreras que ofrece la universidad perfectamente podrían cursarse en cuatro años, y no en cinco, organizando de una manera más eficiente el uso del calendario y podando el currículum de contenidos superfluos o redundantes. Esto implicaría un ahorro en la inversión y una disminución en el costo de oportunidad para los estudiantes.

Cuarta: El tiempo debe ser aprovechado con intensidad. Muchas universidades trabajan 32 de las 52 semanas que tiene cada año, al ofrecer tan solo dos semestres, de 16 semanas cada uno, como programación académica. Debería existir una programación continua y el uso intensivo de los meses de verano, estableciéndose un modelo de vacaciones escalonadas para el profesorado y los empleados. En cuanto a los estudiantes, han de hacerse menos laxas las normas de permanencia para impedir que unos cuantos de ellos vegeten largos años en la universidad haciendo perder innecesariamente recursos al Estado.

Quinta: Las universidades deben funcionar integradas en redes regionales, sin desmedro de sus autonomías, para optimizar el uso de los recursos físicos, financieros y humanos que dispongan.

Sexta: Deben establecerse sistemas nacionales y regionales de evaluación y acreditación para los programas de las instituciones del sector universitario. Estos sistemas no pueden ser optativos, sino obligatorios.

Séptima: Hay que respetar por completo el principio establecido en el artículo 103 de la Constitución que señala: la educación impartida en las instituciones universitarias del Estado es gratuita. Si hay algo enfatizado en la Constitución, también, son los principios de solidaridad y corresponsabilidad. Porque si el Estado y la sociedad deben garantizar la equidad para el ingreso y la permanencia de los estudiantes en las instituciones, también debe exigirse a esos estudiantes la práctica de la equidad a partir de su egreso como profesionales, esta última fórmula que acuñó entre nosotros Luis Ugalde. ¿Cómo hacerla? Estableciendo, como propuso alguna vez José Ángel Ferreira, un impuesto del $1 \%$ de su salario a los profesionales egresados de las universidades oficiales y otro impuesto del $0.5 \%$ de su salario a ser pagado por las empresas que los contraten, ambos a beneficio de la universidad pública donde se formaron (Ferreira, 2011, pp. 6-7). Este 
impuesto, que yo llamaría de solidaridad intergeneracional, no afecta ni de lejos el principio de la gratuidad de la enseñanza. Lo que sí acentúa son los principios de la equidad, la solidaridad y la corresponsabilidad.

Octava: Las jubilaciones de los profesores deberían darse a partir de los 35 años de servicio. Porque es necesario saber diferenciar entre un maestro de primaria, que debería ser jubilado después de interactuar cuarenta horas a la semana con niños a lo largo de 25 años de servicio, y un profesor universitario que la tiene indicada a los 25 años de servicio académico. Jubilar a los cincuenta o cincuenta y cinco años de edad a un investigador es un despilfarro que este país no puede seguir manteniendo. Veamos que países con mayor poderío económico que el nuestro, como España, por ejemplo, han alargado la edad de jubilación del profesor universitario hasta los 65 años. ¿Decir esto choca con el mito de los derechos adquiridos? Hay que estar conscientes del país en el que vivimos y de la etapa histórica que transitamos. Cuando José Gregorio Hernández se jubiló, a finales del siglo XIX, con 15 años de servicio, de su cargo de profesor universitario, era porque así lo establecía la legislación del momento, pero esa legislación se formuló en un tiempo histórico en el que la edad promedio de vida del venezolano no sobrepasaba los cincuenta años, mientras que la edad promedio de vida actual es de 73 años y, para el caso de los profesionales, se ubica en torno a los ochenta años...

Novena: Hay que cambiar el modelo de trabajo basado en el tiempo de permanencia del profesor en la institución. Hay que fundarlo, más bien, en el cumplimiento de tareas y la generación de productos con excelencia. Cada profesor debe tener su plan de trabajo anual y de mediano plazo, sea en docencia, sea en investigación o sea en gerencia. Se le debería pagar a cada quien en función de la evaluación que se haga de las tareas que realmente ejecute, de los logros y productos que genere. Se debe acabar con la desestimulante homologación de salarios.

Décima: Finalmente, nos topamos con la necesidad de relativizar un mito muy arraigado en la mentalidad universitaria, un mito hermoso y surgido de las mejores intenciones pero que, como todo mito, no está ajustado a la realidad. Un mito que, pretendiendo hacer mucho bien, ha causado claros perjuicios en lo financiero para las universidades, y muchas e innecesarias vivencias de fracaso existencial a los profesores: es el mito de que todo docente debe ser un investigador.

Este credo tiene algunas décadas imperando entre nosotros, en muchas latitudes, con formulaciones al estilo de las que ahora entrelazaremos, emanadas de las plumas de dos universitarios -César Villarroel y Ernesto Mayz Vallenilla-, de quienes, con mucho respeto, discrepo en este terreno. Decía uno y el otro que "creemos en una docencia y una investigación para todos los profesores universitarios" porque "la auténtica labor del maestro no es solo enseñar, sino coparticipar con sus alumnos en la labor investigativa que exige el genuino cultivo de la ciencia”. De allí que: "docencia e investigación sean universitariamente inseparables (...), la ausencia de una de ellas vulneraría, en consecuencia, la esencia universitaria" (Villarroel, 1990, p. 39).

El problema con estas formulaciones es que confunden la esencia de la corporación y la organización universitaria con lo que deberían ser los ras- 
gos del perfil de los profesores. Cualquier organización compleja tiene tres o cuatro tareas esenciales, pero eso no implica que todos y cada uno de sus miembros tengan que desempeñarlas todas. Eso es obvio. En una fábrica automotriz, por ejemplo, se debe diseñar el modelo de los vehículos, construir sus partes, ensamblarlas y comercializarlas. Eso no quiere decir que cada trabajador deba desempeñar los cuatro oficios...

La consecuencia negativa, en lo financiero, de haber elevado este mito hacia una norma jurídica es que, como todo profesor debería ser investigador y enseñante, se le pauta un tiempo de dedicación a tiempo completo o exclusivo y una remuneración acorde, bajo el supuesto de que necesita tal dedicación para poder producir frutos en ambos campos. Pero no ocurre así. Para 1995, se estimaba que "menos del 13\% del personal académico de tiempo completo y dedicación exclusiva en las universidades realizaba investigaciones de manera regular" (Castillo, 1997, p. 116). Ese estimado de Eduardo Castillo lo corroboró Jaime Requena, quien precisó que, para 1999, de 15.063 profesores de tiempo completo y dedicación exclusiva en las universidades públicas, tan solo 1.409 , un $9 \%$, estaban registrados en el PPI (Requena, 2003a, p. 246).

Digo yo, entonces, que cuando un modelo teórico está desfasado -en magnitudes de un $90 \%$ - de lo real, no hay que empeñarse en continuar engañando a la realidad, sino más bien conviene revisar el modelo teórico. ¿Qué quiero decir? Que por mantener la formulación mítica de que "todo docente debe ser un investigador" se han pagado en balde billones de bolívares a miles y miles de profesores universitarios que, en realidad, no lograron cumplir con su deber de investigar. Si se mantuviera la ficción conceptual y jurídica se mantendría el despilfarro...

¿No sería más realista entender que tal vez, en el mejor de los casos, solo uno de cada cinco profesores, un $20 \%$, es apto para ser un investigador consistente? ¿Por qué intentar forzar las cosas? Porque debo señalar, además, que incluso muchos trabajos de ascenso, hechos a marchas forzadas, en realidad no constituyen aportes para el conocimiento científico, sino que son meras aplicaciones de fórmulas fosilizadas o recetas contenidas en unos fulanos libros de metodología de la investigación. Esos trabajos constituyen el ejercicio intelectual, es verdad, de los profesores que los realizan, pero no constituyen propiamente aportes para la ciencia. Los extremos se tocan. Algunos hipertrofian tanto la importancia de la investigación que, sin darse cuenta, contribuyen a su banalización...

Hay que ser realistas, vuelvo a insistir. La realidad no es bipolar. Ella se descompone en múltiples gradaciones. No es verdad que si no se es investigador insigne se sería un mero repetidor en clases del contenido de unas fichas amarillentas por el paso del tiempo. Existen profesionales con suficientes conocimientos para contribuir de verdad con la formación profesional 


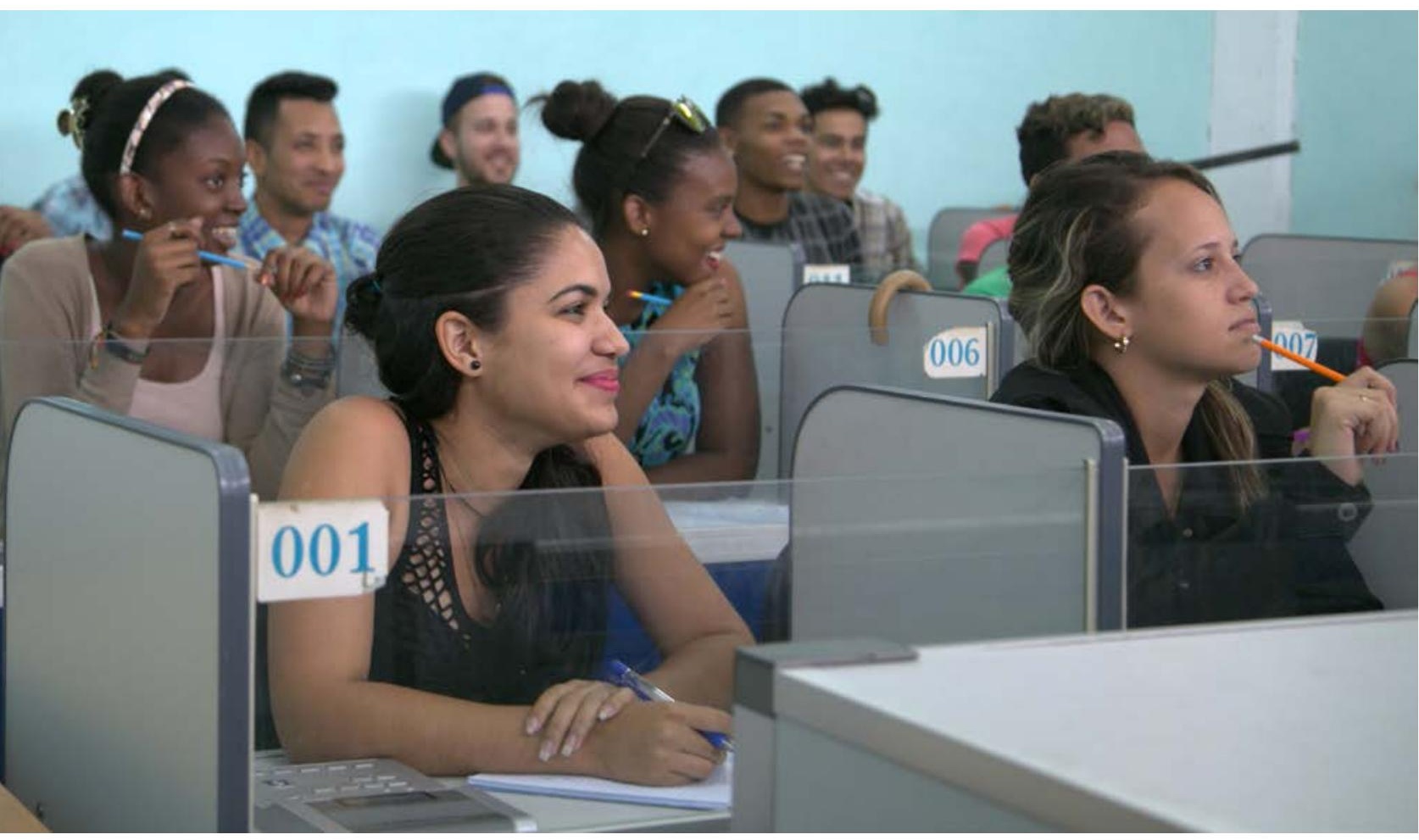

de sus estudiantes y, además, con excelentes habilidades pedagógicas para estimular en ellos la curiosidad, que es la base del aprendizaje. Tales docentes pueden estar permanentemente actualizados en cuanto a los avances de campos científicos sobre los que ellos imparten docencia. Pero muchos de ellos no tienen la capacidad, o tal vez el interés, de trabajar sistemáticamente como investigadores. ¿Por qué estigmatizarlos?

Propongo que se establezcan dos escalafones distintos para quien quiera realizarse como docente y para quien quiera hacerlo como investigador. Es claro que también habrá unos cuantos profesores que recorran simultáneamente ambos caminos. Bienvenidos sean los de este último tipo, tanto como los de los dos primeros. Y también sean bienvenidos los que se destaquen en las tareas de la complicada gerencia institucional. Lo que debe hacer la universidad es reconocerle y pagarle a cada quien de acuerdo con la bondad y la excelencia que demuestre en cada una de las tareas y proyectos relativos a estos tres grandes procesos de trabajo en los que se involucre.

Postulo una universidad realista, que deje de pretender que se guía por hermosas e inútiles ficciones románticas... 


\section{Referencias}

Albornoz, Orlando (1997). La Educación Superior en América Latina y el Caribe, estado del arte, en: UNESCO-CRESALC. La Educación Superior en el siglo XXI, visión de América Latina y el Caribe, tomo 1, UNESCO-CRESALC, Caracas.

Brunner, José Joaquín (1991). Modernidad y Educación Superior, Cuadernos del CENDES, No. 15-16, CENDES, septiembre 1990-abril 1991.

Brunner, José Joaquín (1990). Educación Superior en América Latina: cambios y desafíos. Fondo de Cultura Económica, Santiago de Chile.

Carvajal, Leonardo (2013). Los necesarios cambios organizacionales para un autogobierno universitario eficiente, en: Varios. Gobernabilidad y calidad para la universidad venezolana, Publicaciones UCAB, Caracas, pp. 23-33.

Carvajal, Leonardo (2012). Hacia una universidad sin mitos, en: Varios. Educación para transformar el país, Foro CERPE, Caracas, pp. 163-180.

Carvajal, Leonardo (2011). Autonomía universitaria y libertad de cátedra versus control político, en la historia venezolana, en: Varios. Universidad, política y democracia, Publicaciones UCAB, Caracas, pp. 15-45.

Carvajal, Leonardo (2010). Debajo del conflicto, la crisis estructural, revista SIC, No. 730, Centro Gumilla, Caracas, diciembre, pp. 436-439.

Carvajal, Leonardo (1998). Liberalismo y conservatismo en la organización del trabajo de la Universidad Central de Venezuela, en: Varios. L' université en Espagne et en Amérique Latine du Moyen Age a nos jours, Publications de l' Université de Tours, Francia, pp. 575-586.

Carvajal, Leonardo (1991). El modo de desgobierno universitario, revista El ojo del huracán, No. 7, Caracas, mayo-julio, pp. V-VII.

Castillo, Eduardo. (1997). Pertinencia de la investigación universitaria: el caso Venezuela, en: UNESCO-CRESALC. La educación superior en el siglo XXI visión de América Latina y el Caribe, tomo I, UNESCO/CRESALC, Caracas, p. 116.

Colomine, Luisana. (1994). Sectores políticos rechazan revisión de la autonomía universitaria, diario El Nacional, 25-11-1994, D-1.

Ferreira, José Ángel. (2011). Gerencia universitaria: componentes presupuestarios, mímeo, Universidad de Carabobo.

García Guadilla, Carmen. (1998). Situación y principales dinámicas de transformación de la educación superior en América Latina, 3ra. Edición, CRESALC/UNESCO/FUNDAYACUCHO, Caracas.

Inciarte, Alicia; Parra, M. Cristina y Ana Julio Bozo. (2010). Reconceptualización de la universidad, IDRC-CRDI, Maracaibo.

Leal, Adela. (1994). Universitarios rechazan pretensión de revisar autonomía universitaria, diario El Nacional, 19-11-1994, D-1.

Leal, Ildefonso. (1981). Historia de la UCV, 1721-1981, Ediciones del Rectorado de la UCV, Caracas.

Lombardi, Ángel. (1995). La universidad sufre de anacronismo funcional, diario El Globo, Caracas, 14-01-1995, p. 9.

Muñoz, Simón. (1994). Defenderemos la autonomía categóricamente, diario El Nacional, 22-111994, C-3.

Parra Pérez, Caracciolo. (1943). Páginas de historia y polémica, Litografía del Comercio, Caracas. República de Venezuela. (1970). Ley de universidades.

República Bolivariana de Venezuela. (1999). Constitución de la República Bolivariana de Venezuela. Requena, Jaime. (2003a). Medio siglo de ciencia y tecnología en Venezuela, FONCIED/PDVSA, Caracas.

Requena, Jaime. (2003b). A propósito del cambio estructural del sector ciencia y tecnología nacional, Revista Venezolana de Ciencia Política, No. 24, Caracas, julio-diciembre 2003.

Salvato, Silvia. (1999). El financiamiento del gasto universitario. Propuestas para un nuevo esquema, en: Varios. Gerencia y financiamiento de la educación superior, Consejo Nacional de Educación/ CONICIT/FUNDAYACUCHO, Caracas, pp. 49-87.

Villarroel, César. (1990). La universidad y su productividad académica, Ediciones Dolvia, Caracas.

134 Universidades $\mid$ núm. 83, enero-marzo 2020| UDUAL | DOI: https://doi.org/10.36888/udual.universidades.2020.83.98 Leonardo Carvajal | Hacia la necesaria superación de algunos mitos de la universidad venezolana 